\title{
EFICIÊNCIA DE DIFERENTES PROTOCOLOS PARA ISOLAMENTO DE Campylobacter jejuni DE CARNE DE FRANGO
}

\section{EFFICIENCY OF DIFFERENT PROTOCOLS FOR Campylobacter jejuni ISOLATION FROM POULTRY MEAT}

\author{
Talita Schneid Tejada1 ORCID - http://orcid.org/0000-0003-2323-7652 \\ Cláudio Dias Timm ${ }^{1 *}$ ORCID - http://orcid.org/0000-0003-3920-9066 \\ ${ }^{1}$ Universidade Federal de Pelotas, Pelotas, RS, Brasil. \\ "Autor para correspondência - timm@ufpel.edu.br
}

\section{Resumo}

Campylobacter jejuni é o principal causador de gastroenterite bacteriana aguda e a carne de frango é um importante veículo do agente. Entretanto, as metodologias convencionais de isolamento de Campylobacter muitas vezes não são eficientes, podendo levar a resultados errôneos. Sendo assim, este trabalho teve como objetivo avaliar diferentes métodos utilizados na detecção de $C$. jejuni em produtos de frango. Carne moída experimentalmente contaminada com três diferentes diluições do microrganismo foi analisada com diferentes protocolos para isolamento de $C$. jejuni. Foram feitas semeaduras diretamente nos ágares mCCDA, Columbia e ágar sangue, e após pré-enriquecimento nos caldos Bolton ou Brucella. As colônias características de Campylobacter foram identificadas e os resultados comparados a fim de avaliar qual o método foi mais eficaz. Os únicos protocolos em que foi possível recuperar o microrganismo de todos os testes foram aqueles em que foi utilizado o ágar mCCDA associado com o Caldo Bolton ou com o Caldo Brucella. Estes foram também os únicos protocolos que permitiram a recuperação de $C$. jejuni 24 horas após a contaminação experimental com inóculo igual a $10^{0} \mathrm{UFC} / 25 \mathrm{~g}$. Entretanto, o ágar mCCDA sem o uso de pré-enriquecimento apresentou desempenho insatisfatório, inferior ao dos demais protocolos. Conclui-se que ágar mCCDA com pré-enriquecimento em caldo Brucella ou em caldo Bolton foram mais eficientes para o isolamento de $C$. jejuni que os demais protocolos.

Palavras-chave: alimentos, segurança alimentar, detecção de patógenos.

\begin{abstract}
Campylobacter jejuni is the main cause of acute bacterial gastroenteritis, and poultry meat is an important agent vehicle. However, the conventional methods for Campylobacter isolation are often not effective and may lead to erroneous results. Thus, this study aimed to evaluate different methods to $C$. jejuni detection in poultry products. Ground chicken experimentally contaminated with three different dilutions of the microorganism was analyzed with different protocols to C. jejuni isolation: Seeding directly in agars mCCDA, Columbia and blood agar, and after pre-enrichment in Bolton or Brucella broth. The Campylobacter characteristic colonies were identified and compared in order to assess which method was the most effective. The only protocols in which it was possible to recover the microorganism from all the tests were those using the mCCDA agar associated with the Bolton broth or the Brucella broth. These were also the only protocols that allowed the recovery of $C$. jejuni 24 hours after the experimental contamination with inoculum equal to $10^{0} \mathrm{CFU} / 25 \mathrm{~g}$. However, the
\end{abstract}


mCCDA agar without the use of pre-enrichment presented an unsatisfactory performance, lower than the other protocols. It is concluded that mCCDA agar with Brucella broth or with Bolton broth preenrichment was more efficient for the $C$. jejuni isolation than the other protocols.

Keywords: food, pathogen detection, food safety.

Recebido em: 13 de maio de 2016

Aceito em: 09 de julho de 2018

\section{Introdução}

Campylobacter é um dos principais agentes de doenças transmitidas por alimentos (DTA) em humanos, constituindo-se na segunda causa mais frequente de diarreias bacterianas nos Estados Unidos $^{(1)}$. Dentre as espécies do gênero, $C$. jejuni é a mais comumente isolada de alimentos e as demais ocorrem com menor frequência ${ }^{(2,3)}$, sendo a carne de frango a principal via de transmissão desse patógeno ${ }^{(4)}$.

A difícil detecção de Campylobacter é um fator negativo no controle da sua disseminação. Esta dificuldade se deve principalmente à composição do alimento, à variada microbiota competidora, ao baixo número de células bacterianas e às difíceis condições de isolamento ${ }^{(5)}$. A característica mais marcante do gênero Campylobacter é a microaerofilia, exigindo baixa tensão de oxigênio para sua multiplicação. $\mathrm{O}$ crescimento é inibido quando a concentração de $\mathrm{O}_{2}$ é menor que $3 \%$ ou maior que $15 \%$, sendo a concentração ideal de $5 \%$. Além disso, requerem cerca de $10 \%$ de $\mathrm{CO}_{2}$ para sua multiplicação ${ }^{(6)}$. Outra característica importante é a faixa bastante estreita de temperatura que os campilobacteres classificados como termofílicos - espécies $C$. jejuni, C. coli e C. lari- se multiplicam, que varia entre $30^{\circ} \mathrm{C}$ e $47^{\circ} \mathrm{C}$, com temperatura de multiplicação ótima de $42^{\circ} \mathrm{C}^{(7)}$. Esses microrganismos são altamente sensíveis ao sal e ao $\mathrm{pH}$ ácido, crescendo na faixa de $\mathrm{pH}$ ótimo próximo ao neutro $(6,5-7,5)$ e com atividade mínima da água em cerca de $0,987^{(8)}$. Além disso, a possível presença de células de Campylobacter spp. viáveis não cultiváveis em resposta a condições de estresse nos alimentos é uma preocupação adicional, uma vez que o isolamento do microrganismo fica dificultado, exigindo etapas para recuperação das células injuriadas, apesar da bactéria poder causar enfermidade caso seja ingerida ${ }^{(9)}$.

Os métodos convencionais ${ }^{(10)}$, além de trabalhosos, exigem vários dias de análise e, muitas vezes, a presença de microbiota competitiva inibe o crescimento de Campylobacter spp., podendo levar a resultados errôneos. Alguns autores ${ }^{(11,12)}$ relatam ser necessário o uso de meios de enriquecimento anteriormente a semeadura em placa, a fim de recuperar células injuriadas; no entanto, outros autores $^{(13,14)}$ afirmam que a utilização de pré-enriquecimento é desnecessária. Deste modo, este trabalho teve como objetivo comparar diferentes protocolos, usando os ágares sangue, Columbia e mCCDA associados ou não com pré-enriquecimento nos caldos Bolton e Brucella, para o isolamento de C. jejuni de produtos de frango.

\section{Material e Métodos}

Porções de $25 \mathrm{~g}$ de carne de frango moída foram contaminadas com $0,25 \mathrm{~mL}$ de inóculo contendo $C$. jejuni ATCC 33291 nas concentrações de $10^{4}, 10^{3}$ e $10^{2} \mathrm{UFC} / \mathrm{mL}$, de forma a serem obtidas as concentrações finais de aproximadamente $10^{2}, 10^{1}$ e $10^{0} \mathrm{UFC} / 25 \mathrm{~g}$ de carne moída, respectivamente. 
As amostras de carne de frango moída foram analisadas quanto à presença de Campylobacter spp. antes da contaminação, utilizando protocolo recomendado pela U.S. Foodand Drug Administration $\mathrm{FDA}^{(15)}$. Uma alíquota de cada amostra utilizada não foi experimentalmente contaminada para servir como controle negativo.

$\mathrm{O}$ experimento foi realizado em triplicata.

Foi realizado segundo $\mathrm{FDA}^{(15)}$, com modificação na incubação no pré-enriquecimento $\left(42^{\circ} \mathrm{C}\right.$ por 48 horas), a fim de padronizar a temperatura e tempo de incubação dos diferentes meios de cultura utilizados no trabalho. Brevemente, $25 \mathrm{~g}$ da carne moída de frango foram acondicionadas, em saco plástico estéril, a 100mL de caldo Bolton (Himedia, Mumbai, India) suplementado com 10mg de Cefoperazona, $10 \mathrm{mg}$ de Vancomicina, $10 \mathrm{mg}$ de Trimetoprim e $5 \mathrm{mg}$ de Anfotericina (Himedia), e homogeneizados por $5 \mathrm{~min}$ em shaker. Após, foi realizada incubação a $42^{\circ} \mathrm{C}$, por 48 horas, em jarras contendo gerador atmosférico de microaerofilia (Microaerobac, Probac do Brasil, São Paulo, Brasil). Passado este período, uma alíquota de $10 \mu \mathrm{L}$ da cultura foi semeada na superfície de ágar Carvão Cefoperazona Deoxycolato modificado (mCCDA, Oxoid, Hampshire, Inglaterra), suplementado com $16 \mathrm{mg}$ de Cefoperazona e $5 \mathrm{mg}$ de Anfotericina B (Himedia) e incubada invertida em jarra de microaerofilia a $42^{\circ} \mathrm{C}$ por 48 horas, para posterior confirmação.

Foram testados dois meios de cultura de enriquecimento. Esta etapa serve para a recuperação de células bacterianas injuriadas, o que poderia aumentar as chances de isolar C. jejuni.

Um dos meios utilizados como enriquecimento foi o caldo Brucella (Acumedia, Michigan, EUA) adicionado de $0,4 \%(\mathrm{~m} / \mathrm{v})$ de carvão ativado, $5 \%(\mathrm{~m} / \mathrm{v})$ de suplemento de solução redutora de oxigênio $\mathrm{FBP}^{(16)}$ e $1 \%(\mathrm{~m} / \mathrm{v})$ de suplemento Campylobacter I (Blaser-Wang) ${ }^{(2)}$ (Himedia), o qual contém antimicrobianos para impedir a multiplicação de outras bactérias.O outro caldo de enriquecimento testado foi o Bolton, suplementado conforme já descrito. Cada amostra de $25 \mathrm{~g}$ foi colocada em saco plástico estéril contendo $100 \mathrm{~mL}$ do caldo, homogeneizada durante $5 \mathrm{~min}$ e incubada em microaerofilia a $42^{\circ} \mathrm{C}$ por 48 horas. Posteriormente, uma alíquota de $10 \mu \mathrm{L}$ de cada cultura foi semeada na superfície de ágar base Columbia (Merck, Darmstadt, Germany) adicionado de 0,4\% de carvão ativado, 5\% de FBP e $1 \%$ de Campylobacter I. Além do ágar Columbia, também foi realizada semeadura de uma alíquota na superfície de ágar sangue Tipo II (Acumedia), adicionado de 5\% de sangue equino desfibrinado e 1\% de Campylobacter I e, ainda, outra alíquota em ágar mCCDA suplementado, conforme descrito anteriormente. Todas as placas foram incubadas invertidas em jarra de microaerofilia a $42^{\circ} \mathrm{C}$ por 48 horas.

Cada produto de frango foi colocado em saco plástico estéril contendo $100 \mathrm{~mL}$ de Água Peptonada Tamponada (APT, Acumedia) e homogeneizado durante $2 \mathrm{~min}$. Alíquotas de $10 \mu \mathrm{L}$ desta solução foram semeadas na superfície de ágar base Columbia, ágar mCCDA e ágar Sangue tipo II, suplementados conforme descrito anteriormente. As placas semeadas foram incubadas invertidas em jarra de microaerofilia a $42^{\circ} \mathrm{C}$, por 48 horas, para depois as colônias serem confirmadas.

As colônias características de Campylobacter nos ágares mCCDA, Columbia e Sangue tipo II foram analisadas morfo-tintorialmente pela coloração de Gram. O gênero Campylobacter é constituído de bactérias Gram negativas com formato de bastonetes delgados espiralados ou em forma de "asa de gaivota" ou"S"; podendo apresentar forma filamentosa ou cocóide nos cultivos de longos períodos ${ }^{(17)}$. Foram realizadas provas de produção das enzimas oxidase e catalase, sendo a espécie $C$. jejuni oxidase e catalase positivas ${ }^{(15)}$.

Após a identificação fenotípica das colônias características, o DNA foi extraído ${ }^{(18)}$ a partir de um pellet de colônias obtido diretamente das placas com as culturas e analisado pela técnica da reação 
em cadeia da polimerase multiplex (multiplex-PCR) para confirmação da espécie C. jejuni, de acordo com protocolo descrito por Harmon et al. ${ }^{(19)}$. Foram utilizados dois pares de primers. O primeiro par (pg3: GAACTTGAACCGATTTG e pg 50: ATGGGATTTCGTATTAAC) amplifica uma região altamente conservada relacionada aos genes da flagelina, tanto em $C$. jejuni como em $C$. coli. O segundo par (C-1:CAAATAAAGTTAGAGGTAGAATGT e GGATAAGCACTAGCTAGCTGAT) amplifica uma região específica somente presente em $C$. jejuni.

\section{Resultados e Discussão}

Em todos os protocolos, tanto com ou sem caldo de pré-enriquecimento, $C$. jejuni foi recuperado das amostras inoculadas com $10^{2} \mathrm{UFC} / \mathrm{g}$ logo após a contaminação e com 24horas de refrigeração, o que provavelmente deveu-se à alta concentração de células bacterianas inoculadas (Tabela 1). Todos os isolados recuperados tiveram a identificação confirmada pela PCR.

$\mathrm{Na}$ concentração de $10^{1} \mathrm{UFC} / 25 \mathrm{~g}$, o microrganismo foi isolado das três amostras apenas quando foi utilizado mCCDA com pré-enriquecimento, tanto com caldo Brucella como com caldo Bolton, independentemente da amostra ser analisada imediatamente após a contaminação (hora 0) ou após 24 horas sob refrigeração. Por outro lado, na semeadura direta em ágar, o mCCDA foi o que apresentou o pior resultado, não havendo recuperação em nenhuma das amostras, tanto na hora 0 como após 24 horas. Entretanto, os resultados das semeaduras diretas em ágar também não foram satisfatórios com o uso dos ágares Columbia e Sangue, uma vez que com nenhum deles foi possível recuperar $C$. jejuni das três amostras contaminadas. No caso da semeadura direta em ágar Columbia, houve recuperação de duas amostras contaminadas com $10^{1} \mathrm{UFC} / 25 \mathrm{~g}$, mas o microrganismo não foi recuperado de nenhuma das amostras contaminadas com $10^{0} \mathrm{UFC} / 25 \mathrm{~g}$. Isso pode ter ocorrido devido à grande multiplicação de bactérias contaminantes observadas nas placas, as quais podem ter inibido a multiplicação de C. jejuni, encontrado em concentração bem inferior nessas amostras.

Tabela 1. Presença de $C$. jejuni em $25 \mathrm{~g}$ de carne moída de frango experimentalmente contaminada com diferentes concentrações bacterianas $(n=3)$ analisadas imediatamente após a contaminação (Hora 0) e após 24horas de refrigeração (Hora 24)

\begin{tabular}{|c|c|c|c|c|c|c|}
\hline \multirow[t]{3}{*}{ Protocolos de isolamento } & \multicolumn{6}{|c|}{ Concentrações bacterianas } \\
\hline & \multicolumn{3}{|c|}{ Hora 0} & \multicolumn{3}{|c|}{ Hora 24} \\
\hline & $10^{2}$ & $10^{1}$ & $10^{0}$ & $10^{2}$ & $10^{1}$ & $10^{0}$ \\
\hline Ágar mCCDA direto & +++ & $-\cdots$ & $-\cdots$ & +++ & --- & --- \\
\hline Ágar Columbia direto & +++ & ++- & -- & +++ & ++- & -- \\
\hline Ágar Sangue direto & +++ & $+\ldots$ & +-- & +++ & --- & -- \\
\hline Caldo Bolton e ágar mCCDA* & +++ & +++ & +++ & +++ & +++ & +++ \\
\hline Caldo Bolton e ágar Columbia & +++ & -++ & --+ & +++ & ++- & --- \\
\hline Caldo Bolton e ágar Sangue & +++ & +-+ & +-- & +++ & $+\ldots$ & -- \\
\hline Caldo Brucella e ágar mCCDA & +++ & +++ & +++ & +++ & +++ & +++ \\
\hline Caldo Brucella e ágar Columbia & +++ & +-+ & --+ & +++ & -- & -- \\
\hline Caldo Brucella e ágar Sangue & +++ & ++- & +-- & +++ & -- & -- \\
\hline
\end{tabular}

+ Presença de C. jejuni em 25g da amostra; - Ausência de C. jejuni em 25g da amostra; * Padrão-ouro. 
A associação dos ágares Columbia e Sangue com pré-enriquecimentos não melhorou o seu desempenho na recuperação de $C$. jejuni das amostras contaminadas com $10^{1} \mathrm{UFC} / 25 \mathrm{~g}$, chegando mesmo a não haver recuperação em nenhuma das amostras após 24 horas de refrigeração, quando foi utilizado o caldo Brucella.

$\mathrm{Na}$ semeadura direta em ágar Sangue, assim como nos ágares Columbia e Sangue após préenriquecimento em Caldo Brucella, o microrganismo foi recuperado na hora 0 de pelo menos uma amostra em todas as concentrações usadas na contaminação experimental, mas na hora 24 C. jejuni só foi recuperado na maior concentração de contaminação $\left(10^{2} \mathrm{UFC} / 25 \mathrm{~g}\right)$. Neste caso, além da população bacteriana acompanhante, $C$. jejuni pode ter sido inibido pela temperatura de refrigeração. Lawley ${ }^{(8)}$ relata que estas bactérias podem sobreviver durante um curto período de tempo a temperaturas de refrigeração e que morrem lentamente em temperaturas congelantes. Além disso, células submetidas ao frio sofrem alterações tornando-se sensíveis à temperatura de $42^{\circ} \mathrm{C}$ e aos antibióticos polimixina e rifampicina ${ }^{(10)}$.

$\mathrm{Na}$ semeadura direta em ágar mCCDA, a bactéria foi recuperada apenas na maior concentração, entretanto, quando este meio foi associado a pré-enriquecimento, seja com caldo Brucella ou com caldo Bolton, a recuperação de $C$.jejuni ocorreu em todas as amostras, mesmo naquelas contaminadas apenas com $10^{\circ} \mathrm{UFC} / 25 \mathrm{~g}$ e após 24horas de refrigeração, o que não aconteceu com os demais protocolos. Esses resultados diferem de outros estudos, como Medeiros et al. ${ }^{(13)}$, que relatam que o plaqueamento direto foi considerado o método mais rápido e eficiente, além de apresentar menor custo por não serem utilizados métodos de enriquecimento. No entanto, estes autores analisaram apenas carcaças de frango resfriadas naturalmente contaminadas, sem avaliar a população de Campylobacter em cada amostra, que poderia ser bastante alta, diferentemente do nosso trabalho, no qual a concentração inicial de $C$. jejuni em cada amostra de carne moída era conhecida.

Em 1984, Bolton et al. ${ }^{(20)}$ já relatavam que o uso de pré-enriquecimento no protocolo laboratorial aumentava a recuperação de Campylobacter. Trabalhos mais recentes ${ }^{(11,12)}$ ainda mostram que a utilização de caldos enriquecidos favorece a recuperação de células bacterianas injuriadas, assim como observado em nosso trabalho. Entre os caldos de pré-enriquecimento utilizados, o caldo Bolton teve melhor eficiência de recuperação em relação ao caldo Brucella, tendo em vista que o $C$. jejuni foi recuperado de $72,2 \%$ das amostras (39/54) em que o pré-enriquecimento foi o caldo Bolton, enquanto que 66,7\% (36/54) puderam ser recuperados em caldo Brucella. Essa diferença na recuperação de células injuriadas provavelmente esteja relacionada à fonte nutritiva dos caldos, os tipos e a quantidade de nutrientes. As bactérias do gênero Campylobacter não fermentam carboidratos e as peptonas são incluídas no meio como nutrientes. $\mathrm{O}$ caldo Bolton tem na sua formulação extrato de levedura ( $5 \mathrm{~g} /$ litro) e ácido alfa-cetoglutárico, um intermediário do ciclo do ácido tricarboxílico, já o caldo Brucella apenas extrato de levedura ( $2 \mathrm{~g} /$ litro) como fonte nutritiva. O ácido alfa-cetoglutárico é um composto de importante atividade biológica produzido na desaminação do glutamato e um intermediário no ciclo dos ácidos tricarboxílicos ${ }^{(10)}$. Outra possibilidade diz respeito à suplementação dos meios, já que no caldo Bolton utilizou-se sangue desfibrinado e no caldo Brucella carvão ativado e antioxidante. Estas substâncias adicionadas aos meios de cultura servem para prevenir o acúmulo e neutralizar os derivados do oxigênio produzido durante a multiplicação nos meios de cultura, como peróxido de hidrogênio, além de neutralizar os inibidores da trimetropina que são tóxicos para Campylobacter $^{(21)}$. No entanto, a utilização de sangue nos meios além de capturar os componentes tóxicos do oxigênio serve também como fonte de nutriente, assim como as peptonas ${ }^{(10)}$, deixando o meio mais rico para a multiplicação bacteriana. Uma terceira diferença entre os meios utilizados que pode ter influenciado as recuperações são os antimicrobianos, os quais reduzem a competição do Campylobacter com outras bactérias. $\mathrm{O}$ caldo Bolton é suplementado com cefoperazona, que inibe 
bactérias entéricas Gram-negativas e algumas Gram-positivas, vancomicina, que inibe bactérias Gram-positivas, trimetoprim, que inibe Proteus spp., e anfotericina que inibe fungos. Já, o caldo Brucella é suplementado apenas com afotericina e cefoperazona, o que deixa o meio mais suscetível à multiplicação de contaminantes comuns em produtos cárneos.

Dentre os ágares seletivos, com uso de pré-enriquecimento, o que apresentou maior eficácia foi o mCCDA. Os ágares Columbia e Sangue não foram eficientes, o que provavelmente se deve à composição do meio, tendo em vista que as substâncias impedientes adicionadas são as mesmas nos três ágares estudados. No ágar mCCDA, caldo nutriente 2 e caseína ácida hidrolisada fornecem fontes de nitrogênio e vitaminas. Já, no ágar Columbia são peptonas de caseína e carne, além de extratos de coração e levedura. No ágar Sangue tipo II, há peptona proteose, fígado e extracto de levedura. O caldo nutriente é uma infusão altamente nutritiva de carne o que provavelmente torna o meio mais rico que o Columbia e o Ágar Sangue.

Não foi observada diferença entre os caldos de enriquecimento na pesquisa de $C$. jejuni quando utilizados juntamente com o ágar mCCDA. A rica composição do meio permitiu o isolamento das células recuperadas nos caldos, tanto Brucella como Bolton, o que nem sempre foi observado nos demais ágares.

\section{Conclusões}

O método utilizando pré-enriquecimento, seja caldo Brucella ou caldo Bolton, e posterior semeadura em meio seletivo mCCDA foi superior na recuperação de células de $C$. jejuni de produtos avícolas experimentalmente contaminados, em comparação ao plaqueamento direto e o uso de outros ágares, mesmo associados com pré-enriquecimento.

\section{Referências}

1. CDC [Centers for Disease Control and Prevention]. National Center for Emerging and Zoonotic Infectious Diseases. Campylobacter, General information, 2014. Disponível em: http://www.cdc.gov/nczved/divisions/dfbmd/diseases/campylobacter.

2. Silva DT, Tejada TS, Blum-Menezes D, DIAS PA, TIMM CD. Campylobacter species isolated from poultry and humans, and their analysis using PFGE in southern Brazil. International Journal of Food Microbiology. 2016; 217:189-194. Disponível em: doi:10.1016/j.ijfoodmicro.2015.10.025.

3. Wei B, Cha S, Yoon R, Kang M, Roh J, Seo H, Lee J, Jang H. Prevalence and antimicrobial resistance of Campylobacter spp. isolated from retail chicken and duck meat in South Korea. Food Control. 2016; 62:6368. Disponível em: doi:10.1016/j.foodcont.2015.10.013.

4. Perko-Mäkelä P, Alter T, Isohanni P, Zimmermann S, Lyhs U. Distribution of Campylobacter jejuni isolates from Turkey farms and different stages at slaughter using pulsed-field gel electrophoresis and flaAshort variable region sequencing. Zoonoses Public Health. 2011; 58 (6):388-398. Disponível em: doi: 10.1111/j.1863-2378.2010.01383.

5. Silva DT, Tejada TS, Cunha CC, Lopes NA, Agostinetto A, Collares T, Leon PMM, Timm CD. Ocorrência de Campylobacter em carne de frango, fezes de frango e humanas e pesquisa dos genes $c d t$. Arquivo Brasileiro de Medicina Veterinária e Zootecnia. 2014; 66(1):297-304. Disponível em: doi.org/10.1590/S0102-09352014000100040.

6. Doyle MP, Jones DM. Food-borne transmission and antibiotic resistance of Campylobacter jejuni. In: 
Nachamkin I, Blaser MJ, Tompkins LS. Campylobacter jejuni: current status and future trends. Washington: ASM Press, 1992, p. 45-48.

7. Park P. The physiology of Campylobacter species and its relevance to their role as foodborne pathogens. International Journal of Food Microbiology. 2002; 74(3):177-188. Disponível em: doi:10.1016/S01681605(01)00678-X.

8. Lawley R. Campylobacter. Food Safety Watch. 2013. Disponível em: http://www.foodsafetywatch.org/factsheets/campylobacter.

9. Ghaffar NM, Connerton PL, Connerton IF. Filamentation of Campylobacter in broth cultures. Frontiers in Microbiology. 2015; 6:657. Disponível em: doi: 10.3389/fmicb.2015.00657.

10. Brasil. Manual técnico de diagnóstico laboratorial de Campylobacter. Brasília: Ministério da Saúde, 2011. 44p. Disponível em: http://u.saude.gov.br/images/pdf/2015/janeiro/09/manual-tecnico-diagnosticolaboratorial-campylobacter.pdf.

11. Chon J, Kim Y, Kim H, Kim D, Kim H, Song K, Seo K. Supplementation of Bolton broth with triclosan improves detection of Campylobacter jejuni and Campylobacter coli in chicken carcass rinse. International Journal of Food Microbiology. 2014; 81:37-39. Disponível em: doi:10.1016/j.ijfoodmicro.2014.04.006.

12. Williams LK, Jørgensen F, Grogono-Thomas R, Humphrey TJ. Enrichment culture for the isolation of Campylobacters pp: Effects of incubation conditions and the inclusion of blood in selective broths. International Journal of Food Microbiology. 2009; 130(2):131-134. Disponível em: doi:10.1016/j.ijfoodmicro.2009.01.018.

13. Medeiros VM, Bricio SML, Filgueiras ALL, Clementino MBM. Utilização de caldo Bolton no enriquecimento seletivo em comparação ao plaqueamento direto na pesquisa de Campylobacter spp. em carcaças resfriadas de frango. Revista do Instituto Adolfo Lutz. 2012; 71(3):456-461. Disponível em: http://revistas.bvs-vet.org.br/rialutz/article/view/5255/4519.

14. Rodgers JD, Lawes JR, Vidal AB, Ellis-Iversen J, Ridley A, Pleydell EJ, Powell LF, Toszeghy M, Stapleton K, Clifton-Hadley FA. Characteristics and comparative performance of direct culture, direct PCR and enumeration methods for detection and quantification of Campylobacter spp. in broiler caeca. Veterinary Microbiology. 2012; 159(3-4):390-396. Disponível em: doi: 10.1016/j.vetmic.2012.04.011.

15. Hunt JM, Abeyta C, Tran T. Campylobacter. U.S. Food and Drug Administration. Bacteriologicalanalytical manual. Chapter 7. 2001. Disponível em: http://www.fda.gov/Food/FoodScienceResearch/LaboratoryMethods/ucm072616.htm.

16. George HA, Hoffmann PS, Krieg NR, Smimbert RM. Improved media for growth and aerotolerance of Campylobacter fetus. Journal of Clinical Microbiology. 1978; 8(1):36-41. Disponível em: http://www.ncbi.nlm.nih.gov/pmc/articles/PMC275110.

17. Nachamkin I. Campylobacter jejuni. In: Doyle MP, Beuchat LR, Montville TJ. Food Microbiology: fundamental and frontiers. 2th ed. Washington: ASM, 2001. p. 179-192.

18. Sambrook J, Russel DW. Molecular cloning: a laboratory manual. New York: Cold Spring Harbor Laboratory Press, 2001.

19. Harmon KM, Ransom GM, Wesley IV. Differentiation of Campylobacter jejuni and Campylobacter coli by polymerase chain reaction. Molecular and Cellular Probes. 1997; 11(3):195-200. Disponível em: http://www.ncbi.nlm.nih.gov/pubmed/9232618.

20. Bolton FJ, Coates D, Hutchinson DN. The ability of Campylobacter supplements to neutralize photochemically induced toxicity and hydrogen peroxide. Journal of Applied Bacteriology. 1984; 56(1):151157. Disponível em: http://www.ncbi.nlm.nih.gov/pubmed/6706882.

21. Silva N. Manual de Métodos de Análise Microbiológica de Alimentos. 3ed. São Paulo:Varela; 2007. 